JURNAL PENJAMINAN MUTU

LEMBAGA PENJAMINAN MUTU

INSTITUT HINDU DHARMA NEGERI

DENPASAR

\title{
RELEVANSI NILAI PENDIDIKAN KARAKTER DALAM GEGURITAN SUDDHAMALA UNTUK MENINGKATKAN MUTU PENDIDIKAN DI INDONESIA
}

\author{
Oleh \\ Kadek Dedy Herawan \\ SMK PGRI Denpasar \\ dedykadek90@gmail.com \\ I Ketut Sudarsana \\ Institut Hindu Dharma Negeri Denpasar \\ iketutsudarsana@ihdn.ac.id
}

Diterima 01 Juli 2017, direvisi 06 Agustus 2017, diterbitkan 31 Agustus 2017

\begin{abstract}
Geguritan as one of the traditional literature is widely used by the authors to pour the brilliant idea of character education through the medium of art language that is strung together based on the diction that is very ungrateful. Through geguritan, a person has indirectly got a character education that is able to build a good mindset, words and deeds. The development of technology and communication in this era of globalization has gradually eroded the interest of teenagers to know and learn traditional literature. Learners are more interested in the things that smelled of technology, especially social media and override traditional literature, one of which is literature geguritan. Geguritan Suddhamala as one of literature geguritan loaded with character values that can be used as guidance in improving the quality of education quality. The relevance of character education in Suddhamala geguritan is divided into three namely divinity / humanity, humanity, and environment. The entire field of character has relevance to efforts to improve the quality of education in Indonesia.
\end{abstract}

Keywords: Structure, Character Education, Relevance, Geguritan Suddhamala 


\section{PENDAHULUAN}

Kemajuan ilmu pengetahuan dan teknologi yang secara tidak langsung dibarengi dengan mudahnya budaya asing masuk ke dalam kebudayaan masyarakat Indonesia khususnya Bali. Kebudayaan tersebut menyusup tanpa filtrasi, sehingga banyak kebudayaan negatif yang mengikis kebudayaan lokal yang telah tertata rapi sejak dulu kala. Demikian pula budaya kekerasan dan anarkisme sosial turut memperparah kondisi sosial budaya bangsa Indonesia khususnya Bali. Nilai kearifan lokal (local genius) yang santun, ramah, saling menghormati, arif, dan religius seakan terkikis dan tereduksi gaya hidup instan dan modern. Masyarakat sangat mudah tersulut emosinya, pemarah, brutal, kasar, dan vulgar tanpa mampu mengendalikan hawa nafsunya, seperti perilaku para demonstran yang membakar kendaraan atau rumah, merusak gedung, serta berkata kasar, dalam berunjuk rasa yang ditayangkan di televisi. Fenomena itu dapat menjadi representasi melemahnya karakter bangsa ini, yang terkenal ramah, santun, berpekerti luhur, dan berbudi mulia.

Masyarakat, mulai mengabaikan hal-hal positif yang merupakan warisan para leluhur dimana telah dituangkan dalam sastra-sastra. Sastra menjadi salah satu dokumen penting yang mengabadikan buah pikiran leluhur yang mengharapkan generasi berikutnya mendapatkan kehidupan yang lebih baik dan mulia.

Sastra merupakan salah satu materi pembelajaran dalam pelajaran bahasa. Sastra adalah sebuah struktur karya sastra yang sudah dinyatakan dengan segala macam struktur huruf dan tulisan, baik tentang hukum, keagamaan, dan lainya (Antara, 2009 : 1). Sastra merupakan hasil imajinasi pengarang yang dipadukan dengan realita kehidupan yang dialami pengarang yang dituangkan dalam struktur tulisan. Sastra tidak bisa dipisahkan dengan kehidupan manusia, karena sastra merupakan sesuatu yang bisa memberikan keindahan dan merupakan cerminan kehidupan masyarakat ketika sastra itu diciptakan. Sastra selalu hadir di tengah-tengah masyarakat sebagai suatu keindahan yang bisa menghibur, sastra juga bisa dijadikan media untuk menyampaikan nilai pendidikan, moral, keagaman dan sebagainya. Di Bali khususnya, kegiatan bersastra sudah ada sebelum tahun $1700 \mathrm{M}$ dimana terkenal dengan para pujangga seperti Mpu Tantular dan lain sebagainya.

Sastra Bali dibagi menjadi dua yaitu sastra Bali purwa dan sastra Bali anyar. Sastra Bali purwa yaitu sastra yang berkembang sebelum tahun 1910 yang ciri-cirinya adalah masih terikat aturan-aturan dalam penulisan maupun penyampaiannya salah satu contohnya adalah geguritan. Adapun sastra Bali anyar adalah sastra yang berkembang sejak tahun 1910 yang ciri-cirinya sudah mulai berbeda dengan sastra Bali purwa.Sebagai daerah yang terkenal dengan budayanya, Bali memiliki kekayaan budaya yang merupakan warisan dari leluhur dengan kandungan nilai adi luhung dan coraknya yang memiliki daya tarik serta keunikan tersendiri. Kekayaan dan keunikan budaya Bali tersebut dikarenakan Bali memiliki karakteristik dan local genius yang khas, yang pada dasarnya berlandaskan pada ajaran Agama Hindu.

Sastra adalah pengejawantahan jiwa dan perasaan manusia yang dituangkan dalam keindahan bahasa (Sudiara, 2005: 3). Sastra dalam hal ini adalah bahasa yang dituangkan dengan nilai estetika yang menggambarkan kehidupan masyarakat, karya sastra tercipta sebagai perpaduan antara pengalaman lahir dan batin pengarang yang diramu dengan bahasa yang imajinatif. Dalam kasanah kesusastraan Bali, Tinggen (1982 : 27) memaparkan bahwa kesusastraan Bali dapat dikelompokkan menjadi dua golongan yaitu Kesusastraan Bali Purwa (tradisional/klasik) dan Kesusastraan Bali Anyar (modern). Kesusastraan Bali Purwa adalah struktur kesusastraan Bali yang merupakan kekayaan budaya asli Bali, yang 
biasanya ditandai dengan aturan-aturan tradisional yang mengikatnya. Sedangkan Kesusastraan Bali Anyar adalah kesusastraan Bali yang telah mengadopsi struktur-struktur kesusastraan modern. Namun demikian, bukan berarti hanya Kesusastraan Bali Anyar yang berkembang di masyarakat, sedangkan Kesusastraan Bali Purwa menghilang tanpa jejak. Kedua struktur kesusastraan ini tetap bertahan dan berkembang di masyarakat Bali. Kesusastraan Bali Anyar baik yang berupa prosa maupun puisi sama-sama mampu berkembang dan mendapat perhatian dari para pecinta sastra. Kesusastraan Bali Purwa, yang lebih mampu berkembang hanyalah yang berstruktur tembang.

Karya sastra berupa geguritan sangat digemari di Bali (Adnyana, 2007: 4). Banyaklah para pujangga melahirkan geguritan dengan judul yang berbeda, serta keseluruhan masih tetap eksis di Bali. Beberapa contohnya adalah Geguritan Sudhamala, Geguritan Ki Balian Batur, Geguritan Pan Balang Tamak, Geguritan Jaya Prana dan berbagai judul lainnya. Setiap geguritan yang diciptakan dengan mengangkat berbagai lakon cerita, tentunya mengandung berbagai nilai adi luhung yang bermanfaat bagi pembacanya. Nilai dalam kehidupan manusia terkait dengan kegiatan manusia menilai. Istilah nilai adalah kata benda abstrak yang artinya keberhargaan atau kebaikan (Mudana, 2009: 63). Nilai dapat pula diartikan sebagai sesuatu kebenaran yang pantas dikejar oleh manusia. Nilai-nilai yang berlaku ini akan menjadi dasar atau patokan masyarakat dalam berbuat. Wujud nilai dalam kehidupan masyarakat ada beraneka macam, seperti nilai keindahan, nilai keutuhan, nilai kesopanan, nilai pendidikan, dan sebagainya. Nilai-nilai dalam masyarakat dapat disosialisasikan melalui penggunaan berbagai saluran, salah satunya melalui karya sastra.

Demikian halnya dalam sebuah karya sastra yang berstruktur geguritan, penulis atau pengarang dalam menciptakan sebuah geguritan seyogyanya mengemukakan berbagai konflik yang terjadi di masyarakat dengan harapan pembaca menemukan nilainilai kebenaran yang hakiki dari pengalamanpengalaman yang telah terjadi sebelumnya. Hal tersebut tidak dapat dipungkiri, mengingat bahwa nilai-nilai dan ajaran-ajaran kebaikan dalam melaksanakan kehidupan tidak hanya disampaikan dipendidikan formal maupun informal serta hukum-hukum yang berlaku. Sastra merupakan salah satu transfer nilai yang baik digunakan untuk membantu menstruktur karakter manusia, khususnya masyarakat Hindu di Bali. Pada dasarnya sastra merupakan tanggapan pengarang atau penulis terhadap hidup dan kehidupan di masyarakat. Sastra dapat dianggap sebagai hasil imajinasi pengarang yang bertolak dari suatu kenyataan. Segala aspek kehidupan yang ada di dunia ini mampu diramu dengan daya imajinasi untuk menciptakan sebuah karya sastra (Gunatama, 2004: 5).

Tentunya hal yang sama terdapat dalam geguritan. Meski dalam peyampaian sebuah lakon, geguritan mengemukakannya dengan balutan nilai estetika dalam kalimat-kalimat yang imanen dan alur yang imajinatif, pada intinya menyampaikan sebuah gambaran kehidupan masyarakat senyatanya. Dari lakon tersebut, pembaca hendaknya dapat memahami nilainilai adi luhung yang terkandung di dalamnya, sehingga apa yang diceritakan dalam sebuah geguritan dapat menjadi sebuah pengetahuan bagi para pembaca.

Banyaknya geguritan yang ada di Bali, seharusnya perilaku masyarakat akan mengikuti amanat-amanat dan nilai yang terkandung di dalamnya, tetapi hal ini sungguh berada diluar dari harapan para kawiswara. Maraknya pemberitaan kasus-kasus korupsi di tanah Indonesia ini, mencerminkan bahwa nilai kearifan bangsa Indonesia mulai terkikis. Perjuangan para pahlawan zaman dahulu demi mewujudkan Indonesia merdeka serasa sirna melihat oknum para pejabat negara yang 
melakukan tindak pidana korupsi. Para pejabat pemerintah tidak bisa memenuhi harapanharapan dari masyarakat Indonesia.

Para pejabat yang menjadi wakil rakyat tidak lagi mementingkan kepentingan umum, melainkan memenuhi keperluan pribadinya dulu. Untuk memenuhi kehidupan yang sangat mewah pejabat sampai lupa akan tugas dan kewajibannya dalam mengemban harapan masyarakat. Mencari kekayaan sebanyakbanyaknya dengan menggunakan segala macam cara dilakukan oleh pejabat sekarang. Menggunakan uang yang semestinya digunakan untuk kepentingan rakyat digunakan untuk keperluan pribadinya. Yang lebih menyakitkan lagi adalah uang yang didapat tersebut digunakan untuk pesta narkoba, mabukmabukan, dan ikut menjadi pelanggan prostitusi yang sekarang ini menjadi tren topik berita televisi.

Kasus-kasus pidana tersebut mencirikan bahwa nilai kejujuran dan nilai religius yang menjadi karakter bangsa Indonesia menjadi hilang. Para pejabat yang semestinya menjadikan teladan untuk generasi muda malah memberikan contoh yang tidak baik. Sehingga kenakalan remaja sekarang ini banyak ditemui. Bahkan peredaran narkoba sudah sampai kepada generasi muda. Mengkonsumsi narkoba bukan hanya merusak kesehatan para pemakainya sangatlah merugikan juga bagi negara. Kenapa demikian, karena ketika kehabisan uang untuk membeli narkoba sudah tentu akan melakukan perilaku yang kurang baik, seperti: perampokan, penjambretan, pencurian dan lain sebagainya.

Selain hal tersebut banyak tersiar di media massa praktek aborsi illegal sampai seorang ibu tega membuang banyinya di depan kos-kosan yang diperkirakan hasil dari hubungan gelap, anak yang kurang mendapat pendidikan menjadi preman jalanan, tawuran antar pelajar, kenakalan remaja, pergaulan bebas yang meresahkan para orang tua serta masyarakat. Tindak kriminalas akhir-akhir ini menjadi tren dalam pemberitaan di media massa. Para pelajar yang baru menginjak masa remaja zaman sekarang ini sudah mulai mengalami pergaulan bebas. Melakukan hubungan intim yang belum boleh dilakukan ketika masih mengikuti pendidikan atau masa menuntut ilmu.

Kenakalan remaja dewasa ini bukan hanya terjadi karena mengikuti pergaulan bebas yang merusakan masa depannya, melainkan sikap rasa persaudaraan juga mulai menurun. Terbukti sering adanya perkelahian antar pelajar sampai menimbulkan kerusuhan. Moral perilaku para remaja sekarang ini perlu mendapat perhatian. Selain hal tersebut rasa ego para remaja juga semakin tinggi baru tahu sedikit sudah dilebih-lebihkan. Misalnya adanya balapan liar yang diikuti oleh para remaja. Keluyuran tengah malam mengikuti balapan tersebut tanpa memikirkan bahwa besoknya akan sekolah. Fenomena itu dapat menjadi representasi melemahnya karakter bangsa ini, yang terkenal ramah, santun, berpekerti luhur, dan berbudi mulia.

Perilaku remaja yang demikian sudah menjauhi dari setiap nilai-nilai karakter Pancasila sebagai dasar negara Indonesia. Merosotnya nilai Ketuhanan jarang mendekatkan diri kepada Tuhan yang menyebabkan perilaku tersebut terjadi. Nilai kemanusian yang mengajarkan saling hormat-menghormati anatar sesama manusia muali terkikis. Dengan terkikisnya nilai kemanusiaan sudah tentu persatuan dan kesatuan menjadi hilang. Menguranginya perilaku taat menjalankan agama, saling menghormati serta sikap bersatu saling membantu sesama manusia menyebabkan generasi muda mentalnya terjerus ke hal-hal negatif.

Sebagai bangsa yang beradab dan bermartabat, situasi yang demikian jelas tidak menguntungkan bagi masa depan bangsa, khususnya dalam melahirkan generasi masa depan bangsa yang cerdas, bijak, terampil, cendekia, berbudi pekerti luhur, berderajat mulia, berperadaban tinggi, dan senantiasa 
berbakti kepada Tuhan yang Maha Esa. Oleh karena itu, dibutuhkan paradigma pendidikan kejiwaan yang berorientasi pada karakter bangsa, yang tidak sekadar memburu kepentingan kognitif (pikir, nalar, dan logika), tetapi juga memperhatikan dan mengintegrasi persoalan moral dan keluhuran budi pekerti. Oleh karena itu perlu pengkajian terhadap nilai sebuah geguritan, untuk merevitalisasi karakter adiluhung yang dimiliki oleh masyarakat Bali yang bisa dijadikan pedoman dalam meningkatkan mutu pendidikan di Indonesia.

\section{PEMBAHASAN}

Geguritan Suddhamala yang merupakan salah satu karya sastra tradisional Bali sangat banyak berisi nilai yang pasti mampu memberikan pengaruh positif berupa pembentukan karakter dimana karya sastra geguritan Suddhamala itu diperdengarkan. Dalam era teknologi dewasa ini penyebaran nilai positif tidak hanya bisa dinikmati dalam lingkup kecil dimana para seniman melantunkan geguritan itu. Speaker yang sering dipasang di Pura atau dimanapun tempat-tempat melantunkan geguritan Suddhamala tersebut akan membantu masyarakat yang walaupun sedang berada dirumahnya akan mendengarkan, sehingga pendidikan karakter dari geguritan tersebut juga masuk kedalam hati pendengar baik pendengar yang masih muda ataupun dewasa. Penikmat sastra/ pendengar akan mengilhami tokoh-tokoh yang diceritakan dalam geguritan Suddhamala tersebut.

Karya sastra geguritan Suddhamala tersebut ketika dipahami dapat mempengaruhi pola pikir dalam berperilaku yang memiliki nilai karkter bangsa yang ditetapkan menjadi pokok pengembangan oleh bangsa Indonesia. Peranan Geguritan Suddhamala terhadap kehidupan masyarakat dapat berperan dalam membentuk karakter yang berbudi pekerti luhur, sehingga mampu mewujudkan tujuan pendidikan nasional untuk mengubah bangsa Indonesia kearah yang lebih baik.

Geguritan Suddhamala merupakan cerita yang tokoh-tokohnya memberikan cerminan untuk hidup memiliki nilai karakter yang positif. Tokoh Sang Suddhamala menggambarkan seorang tokoh memiliki karakter religious, humanity dan evironment dimana selalu bersyukur dalam menjalani hidup, rendah hati dan suka membantu. Selain itu tokoh-tokoh yang lain seperti Yudistira, Bima, Arjuna, Nakula, Rsi Tamba Petra, Dewi Uma, Dewa Siwa, I Patut dan lain-lain juga memberikan ajaran-ajaran karakter bagaimana seharusnya bersikap didunia ini. Karakter yang ditunjukkan oleh tokoh-tokoh dalam Geguritan Suddhamala memiliki relevansi terhadap peningkatan mutu pendidikan di Indonesia.

\subsection{Relevansi Nilai Pendidikan Karakter Religius}

Karakter religius merupakan sikap dan prilaku yang patuh dalam melaksanakan ajaran agama yang dianutnya, toleran terhadap pelaksanaan ibadah agama lain, dan hidup rukun dengan pemeluk agama lain (Yaumi, 2014: 60). Karakter religius akan membentuk manusia yang beriman kepada Tuhan Yang Maha Esa. Memiliki karakter religius dan beriman akan membentuk sikap dan prilaku manusia yang baik, serta menunjukkan keyakinan akan adanya kekuatan Sang Pencipta. Keyakinan adanya Tuhan akan mewujudkan manusia yang taat beribadah dan berprilaku yang sesuai dengan apa yang dianut oleh agama dan tidak melakukan apa yang dilarang oleh agama.

Pada dasarnya agama atau religi juga mengutamakan aspek moral dan etika dalam nilai-nilainya. Pembelajaran pendidikan karakter diberikan melalui aspek-aspek keagamaan atau berbasis pada religi, maka akan membentuk suatu kombinasi yang baik tanpa ada nilai-nilai yang saling berlawanan atau bertolak belakang. Agama merupakan salah satu sumber nilai dalam membangun pembelajaran pendidikan karakter. Sumber keagamaan tersebut 
memunculkan nilai religi sebagai salah satu nilai yang menjadi bagian atau unsur yang membentuk karakter individu (bangsa).

Pembelajaran pendidikan karakter religius yang mencerminkan keyakinan terhadap Tuhan Yang Maha Esa/ Ida Sang Hyang Widhi Wasa dimana mensyukuri segala anugerah yang diberikan oleh Tuhan melalui wujud ucapan terimakasih dalam bentuk pelaksanaan upacara Yadnya dalam Geguritan Suddhamala memiliki kerelevanan terhadap karakter budaya mutu yang dikembangkan pada dunia pendidikan di Indonesia. Relevansi yang dimaksudkan tersebut adalah sebagai berikut.

...//Yan sampun bhatara nywecanin/ malingga ring dewek titiang/micayang kasiden mangkol tumuli raris madabdab/Sang Sahadewa ngarepang/ sarwi manunggalang kahyun/ngastawa Ida Hyang Siwa// (Pupuh Semarandana bait 5)

Terjemahannya:

...//Kalau sudah Bhatara merestui/ bersetana dalam diri hamba/ bemberikan anugerah saat ini/dan selanjutnya bersiap/ Sang Sahadewa mendekat/ serta memusatkan pikiran/ Memuja Dewa Siwa//

...//Sakarura bija kuning/sampun sami cumadang/ Raris ngelarang weda mangko/ Hyang Durga maweweh dukal santukan tan kahyun karuat/ duk ida kadung nyusup/ Durga murtine karangsukang//(Pupuh Semarandana bait 6)

Terjemahannya:

...//Penyucian beras kuning/ sudah semua disiapkan/lalu mengucapkan mantra/Dewi Durga bertambah marah/karena tidak mau disucikan/ karena sudah terlanjur menyusup/dirangsuki Durga Murti//

Kutipan tersebut menjelaskan bahwa rasa syukur Sahadewa setelah mendapatkan restu Tuhan melalui pemusatan pikiran maka segala anugerah Tuhan tersebut akan benar-benar bermanfaat bagi masyrarakat dan dunia ini. Oleh karena itu perlu bersyukur melalui pemusatan pikiran, introspeksi diri dan senantiasa tetap memuja Tuhan melalui ikut melaksanakan upacara Yadnya. Pembiasaan persembahyangan tersebut sebenarnya sudah mulai diajarkan dari peserta didik masih kecil.

Sikap dan perilaku bersyukur kepada anugerah Tuhan juga digambarkan ketika harihari besar seperti Galungan dan Kuningan, maka tidak hanya ibu-ibu dan anak perempuan yang membawa sesaji untuk sembahyang, melainkan seluruh lapisan masyarakat yang masih mampu untuk melaksanakan persembahyangan akan membawa sesaji. Hal ini menjadi suatu contoh yang bagus yang menegaskan bahwa pemusatan pikiran merupakan sebuah kebutuhan bagi semua umant dan semua lapisan masyarakat.

\subsection{Relevansi Nilai Pendidikan Karakter Toleransi}

Nilai-nilai karakter dan budaya bangsa mencantumkan karakter toleransi. Toleran terhadap pluralitas merupakan keharusan untuk membangun suatu kesatuan yang utuh. Secara umum toleransi bersikap adil, objektif, dan permisif terhadap orang-orang yang pendapat, praktik, ras, agama, kebangsaan, dan sebagainya. Toleran yakni sikap yang bebas dari kefanatikan, menerima dan menghargai perbedaan.

Karakter toleransi akan membentuk masyarakat menjadi orang yang bersifat ramah tamah, sehingga menjadi pribadi yang menyenangkan, menenangkan serta membuka pintu kepada orang lain. Karakter toleransi dalam Geguritan Suddhamala bisa dicermati melalui kutipan berikut ini.

...//Yan ipun aturang titiang/napi ucape ring gumi/ yan wantah bilih kangkat/ wenten pianak titiang telu/ silih tunggil aturang titiang/ asing kaapti/ledang pikayun bhataral/(Pupuh Ginada bait 21) 
Terjemahannya:

...//Kalau Sahadewa saya persembahkan/ apa perkataan dunia/ kalaupun diterima/ ada anak saya tiga/ salah satu saya persembahkan/siapapun yang diinginkan/ sesuai permintaan Dewi Durga//

Kutipan tersebut sangat jelas menyampaikan bahwa Dewi Kunti merupakan sosok yang toleran yang tidak mau mengorbankan Sahadewa menjadi tumbal yang mana Sahadewa bukanlah anak kandungnya melainkan anak dari madunya. Kunti lebih memilih mengorbankan apa yang memang menjadi miliknya bukan milik orang lain. Hal ini mengajarkan kepada manusia bahwa sebaiknya tidak mengorbankan orang lain demi kepentingan diri sendiri.

\subsection{Relevansi Nilai Pendidikan Karakter Jujur}

Nilai-nilai karakter dan budaya bangsa selanjutnya adalah karakter jujur. Jujur adalah mengakui, berkata atau memberikan suatu informasi yang sesuai dengan kenyataan dan kebenaran. Berkata tidak sesuai dengan kebenaran dan kenyataan atau tidak mengakui suatu hal sesuai dengan apa adanya, maka orang tersebut dapat dianggap atau dinilai tidak jujur, menipu, berbohong, munafik dan sebagainya. Pendidikan karakter jujur merupakan sesuatu hal yang sangat teramat penting ditanamkan dalam masing-masing pribadi. Perilaku yang tidak suka berbohong dan berbuat curang serta sportivitas akan mewujudkan hubungan yang harmonis dengan Tuhan dan dirinya sendiri. Karakter jujur yang terdapat dalam Geguritan Suddhamala dipaparkan dalam kutipan berikut ini.

...//Apang lega cening ngruat/ malan memene janil Sang Sahadewa manimbal/ ngubakti nyumbah umatur/ Singgih ratu Sang Hyang Durgal ndaweg mangkin/ reh titiang janma muda//Pupuh Ginada bait 32)
Terjemahannya:

...//Agar ananda bersedia menyucikan/ dosa ibu sekarang/ Sang Sahadewa menjawab/menghormat menyembah dan berkata/Baiklah Dewi Durga yang agung/ maafkan saya/karena saya adalah manusia yang masih muda//

...//Tan uning titiang ngruat/ malan titiang tani gigis/tan sida titiang ngruat/ napi malih mulan $i$ ratu/ inggih ampurayang titiang/ ratu bhatari/ sampunang menggah ring arsa// (Pupuh Ginada bait 33)

Terjemahannya:

.../Tidak tahu hamba caranya membersihkan/dosa saya juga tidak sedikit/ tidak bisa hamba menyucikan/apalagi yang mulia Dewi/baiklah maafkanlah saya/yang mulia Dewi janganlah marah//

Kutipan tersebut menyatakan bahwa Sahadewa/Suddhamala merupakan pribadi yang jujur yang mengakui bahwa dirinya tidaklah tahu untuk menyucikan Dewi Durga, karena memang Suddhamala merasa dirinya juga sangat penuh dosa. Dalam kehidupan ini perilaku jujur sangatlah baik dimana ketika tidak bisa melakukan sesuatu janganlah mengaku bisa demi keuntungan tertentu yang akhirnya akan merugikan dan jauh lebih buruk dari keadaan yang seharusnya. Perilaku jujur merupakan simbul dari kebenaran, kebenaran tersebut merupakan ajaran yang disampaikan oleh Tuhan, oleh karena itu berperilaku jujur, berkata jujur dan berfikir jujur juga merupakan jembatan emas untuk mendekatkan diri kepada Tuhan Yang Maha Esa.

\subsection{Relevansi Nilai Pendidikan Karakter Cinta Damai}

Karakter cinta damai merupakan sikap, perkataan dan tindakan yang menyebabkan orang lain merasa senang dan aman atas kehadiran dirinya (Yaumi, 2014: 60). 
Perdamaian juga menunjukkan upaya yang tulus untuk rekonsiliasi, keberadaan kehidupan yang sehat, atau hubungan interpersonal yang baik atau hubungan internasional yang stabil, kemakmuran dalam hal kesejahteraan sosial dan ekonomi, pembentukan kesetaraan, dan tatanan politik kerja politik yang melayani kepentingan sejati dari semua orang. Karakter cinta damai dalam Geguritan Suddhamala dipaparkan dalam kutipan berikut ini.

...//Yening saja tuara nyak/ sing buungan cai mati/ sarwi mangayatang blakas/ jaga manyempal gulu/Singgih Ratu Hyang Durga/ durus mangkin pademang ratu titiang// (Pupuh Ginada bait 35)

Terjemahannya:

...//Kalau benar tidak mau/pastilah engkau akan mati/ serta mengangkat pedang/ akan memenggal/ Baiklah yang mulia Dewi Durga/ silahkan bunuh saya sekarang//

...//Santukan titiang tan sidal manglukat malan bhatari/ becik ratu pademang titiang/ sampunika ida matur/madulur nyerahang angga/raris nyerit/ Hyang Durga mangarepang// (Pupuh Ginada bait 36)

Terjemahannya:

...//Karena saya tidak bisa/ membersihkan dosa yang mulia/ lebih baik yang mulai membunuh saya/ seperti itu beliau berkata/ sambil menyerahkan diri/lalu menjerit Dewi durga sambil mendekat//

Kutipan tersebut memaparkan karakter cinta damai dari Sahadewa/Suddhamala dimana untuk menghindari sesuatu konflik yang tidak beliau inginkan dikemudian hari karena memang sebenarnya belum bisa melakukan penyucian kepada Dewi Durga maka Suddhamala lebih memilih untuk dibunuh sehingga kedamaian bisa terjaga. Dalam kehidupan sebaiknya memiliki rasa cinta damai sehingga mampu membuat dunia ini tentram tanpa adanya konflik yang berujung peperangan dan merugikan umat manusia. Memiliki karakter cinta damai akan membuat semuanya mendapatkan kedamaian termasuk seluruh alam semesta.

\subsection{Relevansi Nilai Pendidikan Karakter Disiplin}

Karakter disiplin merupakan suatu bentuk kepatuhan terhadap peraturan yang dibuat dan dibentuk. Berikut ini kutipan yang memaparkan karakter disiplin tersebut.

...//Singgih ratu Sang Hyang Siwal ampurayang titiang mangkin/ ledangang bhatara ngruwak/ malan titiange tan gigis/bhatara raris nyaurin/ Pastun beli kadung labuh/ tuara dadi jani tulak/ kewala antosang adi/ kala ditu/Disubane roras tiban// (Pupuh Sinom bait 20)

Terjemahannya:

.../Baiklah yang Mulia Dewa Siwa/ maafkanlah diri ini sekarang/mohon agar Dew menyucikan/ dosa saya tidaklah sedikit/ Dewa Siwa lalu menjawab/ Kutukan kanda sudah terlanjur/ tidaklah boleh sekarang ditolak/ tetapi tunggulah dinda/ saat disitu/ setelah duabelas tahun//

Kutipan tersebut memaparkan karakter disiplin Dewa Siwa, dimana yang salah tetap harus dihukum sesuai dengan aturan walaupun itu adalah istri sendiri. Disiplin menegakkan aturan seharusnya dimiliki semua orang agar bisa menjadi panutan.

\subsection{Relevansi Nilai Pendidikan Karakter Kerja Keras}

Karakter kerja merupakan perilaku yang menunjukkan upaya sungguh-sungguh dalam mengatasi berbagai hambatan belajar dan tugas, serta menyelesaikan tugas dengan sebaikbaiknya (Yaumi, 2014: 60). Karakter kerja keras dalam Geguritan Suddhamala terdapat pada kutipan berikut. 
...//Pamargan Ida Sang Nakula/ sada nyilib manyusup alas aripit/ tan wenten rasa pakewuh/ sering ida mararyan/ jlempah-jlempoh/ ngajap-ajap arine ditu/ Uduh adi/ Sahadewal dija ruruh beli jani// (Pupuh Pangkur bait 20)

Terjemahannya:

.../Perjalanan Sang Nakula/ sembunyisembunyi menyusuri hutan yang angker/ tidak ada rasa takut/ sangatlah sering beliau beristirahat/ Sangat lelah/ memanggilmanggil adiknya disitu/ Wahai adikku Sahadewa/ dimana sekarang kakak mencari//

Kutipan tersebut memaparkan karakter kerja keras Nakula untuk menemukan adiknya walaupun dengan menyusuri hutan, jalan terjal, naik gunung menuruni lembah karena tekatnya maka Nakula lalui sehingga Nakula berhasil menemukan Sahadewa yang sudah memiliki nama Suddhamala. Hal ini menandakan bahwa kerja keras merupakan proses kehidupan dan tujuan adalah hasil yang akan didapatkan setelah melalui proses kerja keras.

\subsection{Relevansi Nilai Pendidikan Karakter Rasa Ingin Tahu}

Karakter rasa ingin tahu merupakan sikap dan tindakan yang selalu berupaya untuk mengetahui lebih mendalam dan meluas dari sesuatu yang dipelajarinya, dilihat, dan didengar (Yaumi, 2014: 6). Karakter rasa ingin tahu yang terdapat dalam Geguritan Suddhamala dapat dicermati melalui kutipan berikutini.

...//Ngawit mangkin katuturang/ Ida Sang Hyang Giri Putril mapi-mapi sungkan rahat/ kahyun ida mamintonin makadi ida bhatara/ Bhatari Uma kawuwus/ baktine kalawan nenten/ mugi mangkin ne ungsengin/ Duh dewayu/ mai ja dewa tampakang// (Pupuh sinom bait 2)
Terjemahannya:

...//Sekarang mulai diceritakan/yang mulia Dewi Uma/ Pura-puralah sakit keras/ maksudnya untuk menguji begitulah Dewa Siwa/ Untuk menguji Dewi Uma/ apakah berbakti atau tidak/ semoga sekarang bisa dilaksanakan/Wahai dinda/ marilah dinda mendekat//

Karakter rasa ingin tahu dimiliki oleh Dewa Siwa. Untuk mengetahui apakah Dewi Uma setia atau tidak maka Dewa Siwa melakukan sebuah ujian yaitu berpura-pura sakit. Rasaingin tahu sebaiknya dimiliki untuk membuat pengetahuan menjadi bertambah. Rasa ingin tahu bisa dilakukan dengan melakukan sebuah percobaan untuk mengetahui apa yang ingin diketahui.

\subsection{Relevansi Pendidikan Karakter Menghargai Prestasi}

Karakter yang kelima adalah karakter menghargai prestasi. Menghargai prestasi akan membuat motivasi menjadi bertambah, baik motivasi yang mendapatkan prestasi ataupun yang belum karena akan memacu rasa untuk melakukan hal yang lebih baik lagi. Dalam Geguritan Suddhamala karakter menghargai prestasi dipaparkan melalui kutipan berikut.

...//Hyang Uma raris mamargi/ nampokin Sang Sahadewal tumuli ngandika alon/Uduh cening Sahadewal meme dahating suksma/ baan legan $i$ cening bagus/malan meme sida ruwat/ /(Pupuh Semarandana bait 11)

Terjemahannya:

...//Dewi Uma lalu berjalan/ mendekati Sahadewa/ lalu berbicara pelan/ wahai anakku Sahadewa/ ibu sangat berterimakasih/karena kemauan anakku/ dosa ibu bisa disucikan// 
...//Uli jani i dewa cening/ maparab Sang Sudamala/ bina buin teken ento/ ada upah meme dewa/maka jatukaman dewal mamargi dewa nglaut/ nyujur jagat Prang Alas// (Pupuh Semarandana bait 12

Terjemahannya :

Mulai sekarang ananda/ bernama Sang Suddhamala/ selain itu juga/ ada imbalan dari ibu/ berupa jodoh untuk ananda/ berjalanlah terus/ menuju negara Prang Alas//

Karakter menghargai prestasi dimiliki Dewi Uma yaitu dengan memberi ucapan terimakasih dan hadiah kepada Suddhamala karena berhasil membersihkan segala dosanya. Menghargai prestasi seseorang akan membuat orang lain juga menghargai balik, sehingga dalam hidup ini senantiasa akan saling menghargai.

\subsection{Relevansi Pendidikan Karakter Tanggung Jawab}

Karakter tanggung jawab merupakan sikap dan perilaku seseorang untuk melaksanakan tugas dan kewajibannya, yang seharusnya dia lakukan, terhadap diri sendiri, masyarakat, lingkungan (alam, sosial, dan budaya), negara dan Tuhan Yang Maha Esa (Yaumi, 2014: 61). Karakter tanggung jawab dalam Geguritan Suddhamala terdapat dalam kutipan berikut ini. ...//Ento ia ngantinin para Korawal sapunika Dewi Kunti/ nguduh putrane mayuda/mireng wacanan i biang/sang karo pranamya bakti/ ngraris medal/ makta sanjata utami//

Terjemahannya:

...//Itu mereka bersahabat dengan para Korawa/ begitulah Dewi Kunti/ memerintah putranya berperang/ mendengar perkataan ibu/ keduanya menghormat/ lalu keluar membawa senjata utama//
Karakter bertanggungjawab ditunjukkan oleh Nakula dan Suddhamala ketika diminta berperang untuk melawan Kalanjaya dan Kalantaka. Kewajiban yang dijalankan oleh Nakula dan Sahadewa adalah kewajiban hormat kepada orang tua dan mematuhi perintahnya, tanggung jawab sebagai kesatria untuk membela negaranya dan kewajiban sebagai seorang pangeran dimana harus melindungi segenap rakyatnya. Dalam hidup ini mesti memiliki rasa tanggung jawab, baik tanggung jawab sebagai pribadi, makhluk sosial, tanggung jawab kepada bangsa dan tanah air, keluarga dan Tuhan Yang Maha Esa.

\subsection{Relevansi Nilai Pendidikan Karakter Kreatif}

Karakter kreatif merupakan pembahasan selanjutnya, dimana merupakan sesuatu yang dicerminkan melalui kreatifitas seseorang dalam merencanakan, melaksanakan dan mengevaluasi. Kreativitas muncul melalui beberapa aspek, yaitu aspek meniru, menganalisis dan mencipta. Dalam geguritan Suddhamala juga ditemukan pendidikan karakter kreatif. Pendidikan karakter kreatif itu dicerminkan melalui kutipan berikut ini.

...//Iseng titiang muruk nyurat/ tatwa suddhamala kambil/ anggen muruk ngawi tembang/ nanging twara manut indik/ pupuh basa kirang rawit/ madasar manahe kudhul anggen ngalimbakang satwa/ tan lali nunas aksami/ ring i ratu/ miwah ida dane samyan//(Pupuh sinom bait 1)

Terjemahannya:

...//Iseng saya belajar menulis/mengambil kisah Suddhamala/ saya pakai belajar membuat tembang/ tetapi tidak sesuai dengan sastra yang indah/pupuh dan bahasanya kurang jelas/ didasari kemampuan yang kurang/ pakai untuk menceritakan cerita/tidak lupa mohon maaf/ kemada yang mulia/dan juga anda semuanya// 
Karakter kreatif dalam geguritan ini ditemukan dalam bahasa pengantar pada geguritan ini dimana sang kawi swara/ penulis geguritan ini dengan jelas menyatakan penciptaan geguritan ini melalui sebuah cerita. Penulis geguritan ini juga secara rendah hati mengatakan bahwa karyanya sangatlah kurang bagus walaupun sebenarnya adalah bagus. Kreativitasnyajuga muncul dengan memberikan tanda kapan geguritan ini mulai dirancang. Hal ini menjadi contoh kepada seluruh manusia untuk bisa berkarya dan menghasilkan sesuatu yang indah dengan tidak menyombongkan diri.

\subsection{Relevansi Nilai Pendidikan Karakter Mandiri}

Karakter mandiri merupakan usaha menjalani proses secara mandiri tanpa campur tangan orang lain secara utuh. Mandiri berarti mampu melaksanakan sesuatu dilandasi atas sikap kedewasaan sehingga mampu melaksanakan proses sesuatu dengan baik walaupun dominan dilakukan sendiri. Dalam geguritan ini ditemukan karakteristik mandiri dari tokoh Suddhamala seperti yang termuat dalam kutipan berikut ini.

...//Duke biang ngaturang ring Ida Hyang Durga/ Ring Gandamayu ngunil raris titiang kandikayang/ mangruwat malan idal saking titah Sang Hyang Widhi/prasida titiang/dados Dewi Uma mawali//

Terjemahannya:

...//Ketika ibu mempersembahkan kepada Dewi Durga/ dahulu di kuburan Gandamayu/lalu saya diminta/menyucikan dosa beliau/atas kuasa Tuhan/ saya bisa/ mengembalikan Dewi Durga kembali menjadi Dewi Uma//

Karakter mandiri dalam geguritan ini terdapat dalam sosok Suddhamala yang dipakai persembahan kepada Dewi Durgha dan ditinggal sendiri didalam hutan olehibunya Dewi Kunti yang pada waktu itu sedang dirangsuki
Ni Kalika. Suddhamala dikatakan mandiri karena melalui prosesnya secara sendiri di dalam hutan hingga akhirnya beliau bisa mengembalikan Dewi Durga menjadi Dewi Uma serta mendapat gelar kehormatan Suddhamala. Dalam hidup, wajib untuk mandiri dalam berbagai hal, karena kemandirian akan mampu melatih untuk berpikir cerdas dan menjadi dewasa.

\subsection{Relevansi Nilai Pendidikan Karakter Bersahabat/Komunikatif}

Karakter bersahabat/komunikatif merupakan perilaku yang menunjukkan upaya untuk menjalin persahabatan dengan jalan berkomunikasi kepada semua orang. Dalam geguritan ini semua tokoh protagonis memiliki karakter bersahabat/ komunikatif. Berikut beberapa kutipan-kutipan yang memaparkan tentang karakter bersahabat/komunikatif dalam geguritan Suddhamala ini.

...//Sang Sudamala raris nyembah/ sarwi matur/ Ksamayang titiang mangkin/ titiang putran Ida Sang Pandhu/ panca katah putran ida/ ring Pandhawa/ jagat titiang ratu mpu/ yan mungguing wastan titiang/ Sang Sudamala kaparabin// (Pupuh Pangkur bait 7)

Terjemahannya:

...//Sang Suddhamala lalu menghormat/ serta menjawab/ mafkan saya sekarang/ saya adalah putra dari sang Pandu/ putra beliau ada lima/di pandawa/ asal saya tuan pendeta/kalau nama saya/ bernama sang Suddhamala//

Kutipan ini menyatakan bahwa Suddhamala merupakan sosok yang komunikatif dan bersahabat dengan menghormat kepada Rsi Tamba Petra serta memperkenalkan dirinya agar terjadi keakraban. Sebaiknya memperkenalkan diri ketika hendak bertamu kemana saja, karena setelah saling mengenal maka akan menimbulkan suasana keakraban. 


\subsection{Relevansi Nilai Pendidikan Karakter Peduli Sosial.}

Karakter yang terakhir yaitu peduli sosial. Peduli sosial merupakan sikap dan perilaku seseorang untuk melaksanakan tugas dan kewajibannya sebagai makhluk sosial yang membutuhkan komunikasi sosial. Peduli sosial bisa dilaksanakan dengan menolong seseorang, memberikan nasehat dan sebagainya.

Menunjukkan karakter yang peduli sosial akan membuat mudah dalam bergaul dalam kehidupan bermasyarakat. Dalam geguritan Suddhamala karakter peduli sosial dipaparkan dalam kutipan-kutipan berikut.

...//Bhagawan raris ngandika/ Ento cening tamiune aturin mangkin/ raris katur ring sang bagus/ madulur panyambrama/Inggih durusang/jerone macanang dumun/ Sang Sudamala kagiat/ ngaksinin sang ayu kalih// (Pupuh Pangkur bait 15)

Terjemahannya:

...//Bagawan lalu berkata/ wahai anakku persembahkanlah sekarang kepada tamu itu/ lalu diberikan kepada sang pangeran/ diawali dengan salam/ baiklah silahkan/ tuan menikmati kudapan dulu/ Sang Suddhamala kaget/ melihat kedua putri cantikitu//

Kutipan ini menyatakan bahwa Rsi Tamba Petra merupakan sosok yang peduli sosial dengan memberikan suguhan kepada tamu yang datang ke pasraman beliau. Manusia itu sebaiknya juga peduli sosial kepada para tamu dengan memberikan suguhan apabila memiliki suguhan sehingga akan memunculkan suasana yang akrab.

\subsection{Relevansi Nilai Pendidikan Karakter Peduli Lingkungan}

Peduli lingkungan yang dimaksud adalah bagaimana peserta didik menyayangi dan menghargai lingkungan merupakan usaha peserta didik dalam berbagai ajang seperti perlombaan dan lain sebagainya.

Peduli terhadap lingkungan alam sekitar dengan menjaga kebersihan, keindahan, kerapian, serta keasrian alam akan membawa suasana menjadi nyaman. Peduli lingkungan adalah suatu sikap keteladanan yang bertujuan untuk mewujudkan keselarasan, keserasian, dan kesimbangan antara manusia dan lingkungan hidup, menciptakan insan lingkungan hidup yang memiliki sikap dan tindak melindungi dan membina lingkungan hidup, serta mewujudkan pemanfaatan sumber daya alam secara bijaksana. Karakter peduli lingkungan dalam Geguritan Suddhamala dipaparkan pada kutipan berikut ini:

...//Pangguh parekan sanunggal/ pun I puput/ aran parekan punika/ sedek makedas-kedas ring lebuh/ Sang Sudamala atanya/Jero lanang ndaweg titiang nunas pamungu/ jagat napike wastanya/ sueca jerone nuduhin// (Pupuh pangkur bait 2)

Terjemahannya:

...//Dilihatlah seorang warga/ dia I Puput/ I Puput nama dari warga itu/ yang sedang bersih-bersih didepan pekarangan/ lalu Suddhamala bertanya/ tuan lelaki saya mohon maaf/ Negara apakah namanya/ Mohon tuan memberitahu//

Kutipan tersebut memaparkan karakter peduli lingkungan yang ditunjukkan oleh I Puput. Dimana memang sewajarnya bagi semua orang untuk membersihkan halaman rumah serta lingkungan sehingga bisa mengurangi proses penyebaran penyakit yang disebabkan oleh kurang bersihnya lingkungan tempat tinggal. Sebagai manusia yang berkarakter hendaknya menumbuhkembangkan kecintaan kepada lingkungan. 


\subsection{Relevansi Nilai Pendidikan Karakter Cinta Tanah Air}

Karakter cinta Tanah air merupakan wujud bakti manusia kepada negara yang menaungi lingkungan tempat tinggalnya. Sebaiknya semuanya ikut mempertahankan Tanah Air dari ancaman siapapun juga, karena Tanah Air adalah kehormatan pribadinya. Cinta Tanah Air bisa diwujudkan dengan jalan membela kedaulatan negara, melindungi negara bahkan berjuang sampai titik darah penghabisan demi negara. Karakter cinta Tanah Air dalam Geguritan Suddhamala dipaparkan dalam kutipan-kutipan berikut ini:

...//Ngandika Sang Dharmasunu mangkin/ ring arine/ Sang Bhima Arjunal maosang indik mesehel Sampun nguyang ngebug/ mangendonin teka mai/ tan lian i detia rual ane maka pamucuk/ jalan jani dabdabang/ nandingin ia/ manyentokang kasaktin/ dauhin waduane onya// (Pupuh Dangdang Gula bait 7)

Terjemahannya:

...//Berkatalah sang Darmawangsa sekarang/ kepada adiknya/ Sang Bima dan Arjuna/ menyampaikan keadaan sang musuh/ sudah bergerak menyerang/ datang ketempat ini/ tak lain adalah kedua raksasa/ yang menjadi pemimpinnya/ marilah sekarang hadapi/ melawan mereka/ mempertaruhkan kesaktian/ beritahulah semua prajurit//

Kutipan kutipan tersebut memaparkan karakter cinta tanah air yang ditunjukkan oleh Yudistira, Bima dan Arjuna, Nakula dan Sahadewa/Suddhamala dalam melindungi kerajaan mereka. Mereka rela mengorbankan jiwa dan raga mereka untuk mempertahankan harkat dan martabat kerajaannya.

\section{SIMPULAN}

Pendidikan Karakter yang terdapat dalam Geguritan Suddhamala yaitu nilai pendidikan karakter religius, karakter toleransi, karakter jujur, karakter cinta damai, disiplin, kerja keras, rasa ingin tahu, menghargai prestasi, tanggung jawab, kreatif, mandiri, bersahabat/komunikatif, peduli sosial, karakter peduli lingkungan dan cinta Tanah Air. Relevansi pendidikan karakter dalam Geguritan Suddhamala pada peningkatan kualitas mutu pendidikan mencakup karakter religius, karakter toleransi, karakter jujur, karakter cinta damai, disiplin, kerja keras, rasa ingin tahu, menghargai prestasi, tanggung jawab, kreatif, mandiri, bersahabat/komunikatif, peduli sosial, karakter peduli lingkungan dan cinta Tanah Air. Keseluruhan bidang karakter tersebut memiliki relevansi atau keterkaitan kompetensi lulusan yang harus dihasilkan oleh dunia pendidikan di Indonesia.

\section{DAFTAR PUSTAKA}

Adnyana, Gede Agus Budi. 2011. Susastra Hindu Nusantara. Bali: Gandapura.

Brahim.1969. Drama dalam Pendidikan. Jakarta: Gunung Agung.

Buda Astawa, I Wayan. 2013. Aspek Tutur dalam Geguritan Dharma Sunyata. Skripsi.(Tidak dipublikasikan). Denpasar: Universitas Udayana.

Gautama, Wayan Budha. 2007. Kesusastraan Bali. Surabaya: Paramita.

Gunatama. 2004. Sastra dan Ilmu Sastra (Sebuah Pengantar Teori dan Terapan). Modul (tidak dipublikasikan). Singaraja : Institut Keguruan dan Ilmu Pendidikan Negeri Singaraja.

Granoka, Ida Wayan Oka, dkk. 1996. Tata Bahasa Baku Bahasa Bali. Denpasar: 
Pemerintah Propinsi Daerah Tingkat I Bali.

Gunawan, S.Pd., M.Ag, Heri. 2012. Pendidikan Karakter Konsep dan Implementasi. Bandung: Alfabeta.

Kusinwati. 2009. Mengenal Karya Sastra Lama Indonesia. Jakarta: CV. Pamularsih.

Lickona, Thomas. 2013. Pendidikan Karakter Panduan Lengkap Mendidik Siswa Menjadi Pintar dan Baik. Bandung: Nusa Media.

Prayitno, M.Sc. Ed \& Manullang, Prof. Dr. Belferik. 2011. Pendidikan Karakter dalam Pembangunan Bangsa. Jakarta: PT. Grasindo.

Riken, Made dkk. 1996. Materi Pokok Bahasa Daerah Bali. Jakarta: Derektorat Jenderal Bimbingan Masyarakat Hindu dan Buddha.
Sukada, I Made. 1987. Beberapa Aspek tentang Sastra. Denpasar: Kayumas dan Yayasan Seni Lisibha.

Sura, I Gede. 2001. Pengendalian Diri dan Etika dalam Ajaran Agama Hindu. Jakarta: Hanuman Sakti.

Tabroni. 2001. Pendidikan Masa Kini dan Mendatang. Jakarta: BinaMulia.

Teeuw, A. 1991. Membaca dan Menelaah Sastra. Jakarta: Gramedia.

Widera, I Ketut. 2013. Model Pendidikan Karakter dalam Geguritan Dreman. Tesis. (tidak dipublikasikan) Denpasar: Pascasarjana IHDN.

Yaumi, M.Hum., M.A, Dr. Muhammad. 2014. Pendidikan Karakter Landasan, Pilar \& Implementasi. Jakarta: Kencana. 